\title{
miR-196a-5p promotes metastasis of colorectal cancer via targeting IKBa
}

\author{
He Xin, Chuanzhuo Wang and Zhaoyu Liu* (D)
}

\begin{abstract}
Background: MicroRNA-196a-5p (miR-196a-5p) has been reported to be involved in the metastatic process of several cancers. In present work, we aimed to investigate the effects of miR-196a-5p and its potential target IkBa on migration, invasion and epithelial-mesenchymal transition (EMT) of colorectal cancer (CRC) cells.

Methods: CCK-8 assay, wound healing assay and cell invasion assay were performed to evaluate the cell proliferation, migration and invasion. In vivo metastasis models were used to investigate the tumor metastasis ability. Real-time PCR, immunofluorescence staining or western blot were utilized to detect the expression of miR-196a-5p, $\mid \mathrm{kBa}, \mathrm{p}-\mathrm{IkBa}$, nuclear p65 and EMT markers including E-cadherin, N-cadherin and fibronectin. Dual luciferase reporter assay was carried out to determine whether there is a direct interaction between miR-196a-5p and IkBa mRNA.

Results: Using SW480 cell with miR-196-5p over-expressed plus SW620 and HCT116 cells with miR-196a-5p knockdown, we found that miR-196a-5p promoted cell proliferation, migration and invasion in vitro and facilitated liver metastasis in vivo. We also observed that miR-196a-5p knockdown or NF-kB pathway inhibition up-regulated E-cadherin while down-regulated N-cadherin and fibronectin. By contrast, miR-196a-5p over-expression promoted EMT process of CRC. Data of dual luciferase reporter assay indicated that miR-196a-5p targeted the IkBa. Moreover, miR-196a-5p down-regulated IkBa expression while up-regulated nuclear p65 expression. Additionally, over-expression of IKBa in CRC cells attenuated the effects of miR-196a-5p on cell migration, invasion and EMT.
\end{abstract}

Conclusions: miR-196a-5p may play a key role in EMT, invasion and metastasis of CRC cells via targeting the IKBa.

Keywords: miR-196a-5p, IkBa, Colorectal cancer, Epithelial-mesenchymal transition, Metastasis

\section{Background}

Colorectal cancer is one of the most common malignant tumors in the gastrointestinal tract, and there are about 1.2 million new CRC cases have been reported worldwide every year [1]. During the last decade, the mortality of CRC had reduced by more than $20 \%$ because of the advance in diagnosis and management of CRC [2]. Unfortunately, CRC still causes more than 600,000 deaths per year [1]. The high mortality of CRC is closely correlated with the tumor metastasis, especially the liver metastasis [3]. It has been reported that nearly $25 \%$ CRC patients were with metastatic disease at the time of initially diagnosed and approximately half of them will ultimately develop the metastases $[4,5]$. With the objective of improving the overall survival of CRC

\footnotetext{
* Correspondence: liuzy@sj-hospital.org

Department of Radiology, Shengjing Hospital of China Medical University, 36 Sanhao Street, Shenyang 110004, People's Republic of China
}

patients, it is urgent to seek new biomarkers in the metastatic CRC and find the interventions.

The microRNAs (miRNAs) are a class of small non-coding RNAs with about 22 nucleotides length [6]. A growing number of studies confirmed that miRNAs played an essential role during the progression of cancer via regulating gene expression by a direct interaction with the 3' untranslated regions of the targeted mRNAs [7]. For instance, miR-4775 was a risk factor for CRC metastasis and it promoted the invasion, metastasis and EMT of CRC cells by activation of the Smad7/TGF $\beta$ signaling cascade [8]. Strikingly, one clinical study showed that miR-196a-5p was in a significantly higher level than the normal adjacent colorectal mucosa and its high expression was associated with the lymph node metastasis and poor prognosis of the CRC patients [9]. In addition, an in vitro study demonstrated that miR-196a promoted CRC cells proliferation and prevented the apoptosis [10].

(c) The Author(s). 2019 Open Access This article is distributed under the terms of the Creative Commons Attribution 4.0 International License (http://creativecommons.org/licenses/by/4.0/), which permits unrestricted use, distribution, and 
The above researches indicated that miR-196a-5p was participated in the pathological process of colorectal cancer, while its role and potential regulatory mechanisms in CRC metastasis need to be elucidated.

NF- $\mathrm{KB}$ proteins are transcriptional factors which binding to the target genes to regulate their expression [11]. Activation of NF- $\mathrm{kB}$ pathway has been reported to be involved in the metastasis of different type of cancers recently. One study from Wang et al indicated that STX2 formed a positive signaling loop with NF- $\mathrm{kB}$ that STX2 enhance its own expression by activating the NF- $\mathrm{KB}$ pathway and ultimately facilitate the CRC metastasis [12]. Moreover, it has been elucidated that deactivation of the NF- $\mathrm{kB}$ signaling pathway by Lipocalin2 suppressed the invasion, metastasis and EMT of the CRC cells [13]. These studies inspired us that activation of the NF- $\mathrm{B}$ pathway may make great contribution to the metastatic process of CRC.

In present work, we employed the SW480 cells with miR-196-5p over-expressed plus SW620 and HCT116 cells with miR-196a-5p knockdown to explore the role of miR-196a-5p on CRC migration, invasion and liver metastasis. We further investigated whether miR196a-5p exert its pro-metastatic effects via facilitating the EMT by a direct inhibition of the IкB $\alpha$.

\section{Methods}

\section{Cell culture}

The human colorectal cancer (CRC) cell lines of SW480, SW620 and HCT116 were obtained from Shanghai Zhong Qiao Xin Zhou Biotechnology Co., Ltd. and cultured in DMEM medium (Gibco, USA) supplemented with $10 \%$ fetal bovine serum (BI, USA) at $37^{\circ} \mathrm{C}$ in $5 \% \mathrm{CO}_{2}$. In order to evaluate the influence of NF- $\mathrm{BB}$ pathway on the migration, invasion and EMT of CRC cells, cells were treated with NF- $\mathrm{KB}$ pathway inhibitor BAY 11-7082 $(10 \mu \mathrm{M}$, medchemexpress, USA) for $48 \mathrm{~h}$ before following experiments.

\section{IKBa plasmid construction and cell transfection}

In order to construct the I $\mathrm{KB} \alpha$ expression plasmid, the full-length cDNA of ІкB $\alpha$ was amplified and inserted into pcDNA3.1 vector with HindIII and BamHI sites. Lipofectamine 2000 (Invitrogen, USA) was employed to transfect IKB $\alpha$ plasmid into SW480 cells. Further, miR-196a-5p mimics, NC mimics, miR-196a-5p inhibitor and NC inhibitor purchased from Shanghai GenePharma Co., Ltd. were transfected into CRC cells using the Lipofectamine ${ }^{\circ}$ RNAiMAX (Invitrogen, USA) following the manufacturer's protocol.

\section{Lentivirus infection}

The lentiviral (LV) particles that over-expressing miR-196a-5p (LV-miR-196a-5p) and its negative control
(LV-NC) or silencing miR-196a-5p (LV-anti miR-196a$5 \mathrm{p})$ and its negative control (LV-anti NC) were purchased from Wanleibio Co., Ltd. CRC cells were seeded in 6-well plates at a density of $4 \times 10^{5} /$ well. $24 \mathrm{~h}$ latter, the lentivirus was added into the culture medium to infect the CRC cells. After screening with Purine toxin (Solarbio, China), CRC cells with stable miR-196a-5p over-expressed or knockdown were obtained.

\section{Dual luciferase reporter assay}

The 3'-UTR region of wide-type of IкB $\alpha$ was amplified and inserted into pmirGLO plasmid at Nhe I and Sal I sites. Furthermore, miR-196a-5p mimics or the miR196a-5p mutant was cotransfected with Luc-IкB $\alpha$ or the control into HEK $293 \mathrm{~T}$ cells using the Lipofectamine 2000 (Invitrogen, USA). Luciferase assays were carried out with the Dual-Luciferase Reporter Assay System (Promega, USA) referring to the instructions.

\section{Real-time PCR}

The total RNA from CRC cells in different conditions was extracted using the TRIpure kit (BioTeke, China). After quantization of concentration, RNA was reversely transcribed into cDNA by the Super M-MLV reverse transcriptase (BioTeke). Quantitative PCR was carried out to determine the expression levels of miR-196a-5p and IKB $\alpha$ using $2 \times$ Power Taq PCR MasterMix (BioTeke) and SYBR Green (Solarbio, China). The procedure for IKB $\alpha$ was as follows: first cycle including $94{ }^{\circ} \mathrm{C}$ for 5 min, $94{ }^{\circ} \mathrm{C}$ for $10 \mathrm{~s}, 60^{\circ} \mathrm{C}$ for $20 \mathrm{~s}, 72^{\circ} \mathrm{C}$ for $30 \mathrm{~s}$, and then 40 cycles of $72^{\circ} \mathrm{C}$ for $2 \min 30 \mathrm{~s}, 40^{\circ} \mathrm{C}$ for $1 \min 30$ s, melting from $60^{\circ} \mathrm{C}$ to $94{ }^{\circ} \mathrm{C}$ for $1 \mathrm{~s}$ every $1{ }^{\circ} \mathrm{C}$. While the miR-196a-5p expression level was measured under following condition: $94{ }^{\circ} \mathrm{C}$ for $2 \mathrm{~min}, 94{ }^{\circ} \mathrm{C}$ for $15 \mathrm{~s}, 60^{\circ} \mathrm{C}$ for $15 \mathrm{~s}, 72^{\circ} \mathrm{C}$ for $15 \mathrm{~s}$ followed with 40 cycles of $72^{\circ} \mathrm{C}$ for $2 \mathrm{~min} 30 \mathrm{~s}, 40^{\circ} \mathrm{C}$ for $5 \mathrm{~min} 30 \mathrm{~s}$, melting from $60^{\circ} \mathrm{C}$ to $94{ }^{\circ} \mathrm{C}$ for $1 \mathrm{~s}$ every $1{ }^{\circ} \mathrm{C}$. The data were calculated by $2^{-\Delta \Delta \mathrm{Ct}}$ or $2^{-\Delta \mathrm{Ct}}$ method and sequences information was shown in Table 1.

\section{CCK-8 assay}

CRC cells were seeded into 96-well plates at $3 \times 10^{3} /$ well. The cell viability was measured at $12 \mathrm{~h}, 24 \mathrm{~h}, 48 \mathrm{~h}$ and $72 \mathrm{~h}$ after transfection. CCK-8 regent (KeyGEN Bio$\mathrm{TECH}$, China) was added into culture medium $10 \mu \mathrm{l}$ per well. After $1 \mathrm{~h}$ incubation, the optical density of solution was measured using a microplate reader at $450 \mathrm{~nm}$.

\section{Wound healing assay}

The transfected or infected CRC cells were cultured in serum-free DMEM containing mitomycin C (Sigma, USA) for $1 \mathrm{~h}$. Subsequently, a sterile $200 \mu \mathrm{l}$ pipette tip was employed to cause scratches. Representative images 
Table 1 Primers used in Real-time PCR

\begin{tabular}{|c|c|}
\hline Name & Sequences \\
\hline \multirow[t]{3}{*}{ hsa-miR-196a-5p } & F: CCGACGTAGGTAGTTCATGTT \\
\hline & R: GTGCAGGGTCCGAGGTATTC \\
\hline & $\begin{array}{l}\text { RT:GTTGGCTCTGGTGCAGGGTCC } \\
\text { GAGGTATTCGCACCAGAGCCAA } \\
\text { CCCCAAC }\end{array}$ \\
\hline \multirow[t]{3}{*}{ hsa-U6 } & F: CTCGCTTCGGCAGCACA \\
\hline & R: AACGCTTCACGAATTTGCGT \\
\hline & $\begin{array}{l}\text { RT:GTTGGCTCTGGTGCAGGGT } \\
\text { CCGAGGTATTCGCACCAGAGC } \\
\text { CAACAAAATATGG }\end{array}$ \\
\hline \multirow[t]{2}{*}{$\mathrm{IkBa}$} & F: CATCCTGAAGGCTACCAACTAC \\
\hline & R: CATCAGCACCCAAGGACAC \\
\hline \multirow[t]{2}{*}{$\beta$-actin } & F: CTTAGTTGCGTTACACCCTITCTTG \\
\hline & R: CTGTCACCTTCACCGTTCCAGTTT \\
\hline
\end{tabular}

$F$ Forward, $R$ Reserve

of cells migrating into wounds were taken at $0 \mathrm{~h}, 24 \mathrm{~h}$ or $12 \mathrm{~h}$ after the scratch.

\section{Cell invasion assay}

Cell invasion assay was performed on 24-well transwell chambers coated with Matrigel (BD, USA). In brief, the upper chamber was added into $200 \mu \mathrm{l}$ DMEM containing $1 \times 10^{4}$ CRC cells and the lower chambers were filled with $800 \mu$ l culture medium containing 30\% FBS. After $24 \mathrm{~h}$ incubation, migrated cells were fixed with $4 \%$ paraformaldehyde for $20 \mathrm{~min}$ and stained with the crystal violet (Amresco, USA) for $5 \mathrm{~min}$. Cells on lower surface were counted with an inverted microscope.

\section{In vivo tumor metastasis assay}

To assess the effects of miR-196a-5p on tumor metastasis, we employed 4-week-old BALB/c nude mice to establish in vivo metastasis models. The thymic aplasia of the nude mice results in immunodeficiency and could avoid interference from host immune system. The nude mice used in present study were obtained from Beijing HFK Bioscience Co., Ltd. (Beijing, China; License number: SCXK (Jing) 2014-0004) and housed in a standard laboratory environment ( $12 \mathrm{~h}$ day-night cycle; temperature: $25 \pm 1{ }^{\circ} \mathrm{C}$; humidity: $50 \pm 5 \%$ ). During the experiments, mice were free access to the water and food and no adverse events were observed. In present work, 24 mice were randomly divided into four groups: SW480-LV-NC group $(n=6) ;$ SW480-LV-miR-196a-5p group $(\mathrm{n}=6) ; \mathrm{HCT} 116-\mathrm{LV}$-anti $\mathrm{NC}$ group $(\mathrm{n}=6)$; HCT116-LV-anti miR-196a-5p group $(n=6)$. According to the experimental group dividing, $2 \times 10^{6}$ transfected CRC cells were injected into spleens of the anesthetized nude mice and the spleens were resected $48 \mathrm{~h}$ latter. All mice were sacrificed 7 weeks after the injection and the hepatic metastases have been evaluated.

\section{H\&E staining}

The fixed liver tissues were embedded in paraffin followed with slicing into $5 \mu \mathrm{m}$ sections. After dewaxing, the sections were stained with hematoxylin (Solarbio, China) and eosin (Sangon, China). The metastatic foci were observed under the OLYMPUS DP73 microscope.

\section{Western blot assay}

CRC cells or liver metastatic tissues were lysed with RIPA Lysis Buffer (Beyotime, China) containing 1\% PMSF (Beyotime). Besides, the nuclear protein was isolated by the Nuclear and Cytoplasmic Protein Extraction Kit (Beyotime). Protein from different conditions were separated by $6-14 \%$ SDS-PAGE and then transferred to PVDF membranes. After blocking with 5\% non-fat milk or $1 \% \mathrm{BSA}$, the membranes were incubated with following primary antibodies at $4{ }^{\circ} \mathrm{C}$ overnight: anti-E-cadherin (1:1000, 60,335-1-Ig, Proteintech, China), anti-N-cadherin (1:1000, 66,219-1-Ig, Proteintech, China), anti-fibronectin (1:500, 15,613-1-AP, Proteintech, China), anti-p-IкB $\alpha$ (1:500, bs-2513R, Bioss, China), anti-IkB $\alpha$ (1:500, bs-1287R, Bioss, China), anti-p65 (1:500, 10,745-1-AP, Proteintech, China), anti- $\beta$-actin (1:500, KGAA001, KeyGen, China) and Histone H3 (1:2000, AM8433, ABGENT, USA). After rinsed with TSBT, the membranes were incubated with their corresponding secondary antibodies at $37^{\circ} \mathrm{C}$ for $45 \mathrm{~min}$. The protein bands were visualized using the ECL reagent (Beyotime).

\section{Immunofluorescence staining}

The CRC cells were seeded on slides and then fixed in $4 \%$ paraformaldehyde for $15 \mathrm{~min}$. After permeabilized with $0.1 \%$ tritonX-100 (Beyotime, China) for $30 \mathrm{~min}$ at room temperature, the slides were blocked with goat serum (Solarbio, China). Subsequently, cells were incubated with antibodies of E-cadherin (1:100, 60,335-1-Ig, Proteintech, China), N-cadherin (1:100, 66,219-1-Ig, Proteintech, China), Fibronectin (1:50, 15,613-1-AP, Proteintech, China) overnight at $4{ }^{\circ} \mathrm{C}$. Then CRC cells were incubated with the goat anti-rabbit $\mathrm{Cy} 3$-conjugated IgG (1:400, A0516, Beyotime) or goat anti-mouse Cy3-conjugated IgG (1:400, A0521, Beyotime). Lastly, cells were counterstained with DAPI (Sigma, USA) before capturing images using the fluorescence microscope (Olympus, Japan).

\section{Statistical analysis}

The data were presented as mean $\pm \mathrm{SD}$ and were obtained from at least three individual experiments. One-way or two-way ANOVA test followed with post 
hoc Bonferroni's test were used to analyze data. While the statistical difference between two groups were analyzed by student $\mathrm{t}$ test. Correlations were analyzed using Pearson's correlation test. A $P<0.05$ was seen as statistically significant.

\section{Results}

miR-196a-5p promoted the cell proliferation of CRC cells We firstly performed Real-time PCR to detect the expression level of miR-196a-5p in various CRC cell lines. As shown in Fig. 1a, the primary colon cell SW480 revealed a lowest expression of miR-196a-5p, while the metastatic colon cell SW620 depicted a 4.05-fold elevation of miR-196a-5p than SW480. We also observed that miR-196a-5p was highly expression in HCT116 cell while weak expression in Caco-2 and LoVo cell lines.

We then assessed whether the expression level of miR-196a-5p in CRC cells influence their proliferation. With this objective, we used miR-196a-5p mimic and inhibitor to induce or silence the miR-196a-5p expression in CRC cells (Fig. 1b, c and d). The results of CCK-8 demonstrated that over-expression of miR-196a-5p significantly accelerated the cell proliferation, while the cell viability was lower in miR-196a-5p-silenced cells than the control (Fig. 1e, f and g).

miR-196a-5p facilitated the migration and invasion of CRC cells

We subsequently investigated the influence of miR-196a-5p on the cell mobility. Data from wound healing assay indicated that over-expression of miR$196 a-5 p$ in SW480 cells enhanced the migration rate to $26.30 \pm 2.70 \%$ and $50.83 \pm 4.11 \%$ at 12 and $24 \mathrm{~h}$, respectively (Fig. 2a). We also observed that knockdown of miR-196a-5p in SW620 and HCT116 cells decreased the migration rates at $24 \mathrm{~h}$ (Fig. 2a). Interestingly, The SW480 cell migration at $24 \mathrm{~h}$ was higher than that of SW620 cells $[14,15]$. We further found that over-expression of miR-196a-5p in SW480 cells increased the number of invading cells by $31 \%$, while knockdown of miR-196a-5p reduced the invading cells by $35-55 \%$ in SW620 and HCT116 cells (Fig. 2b).
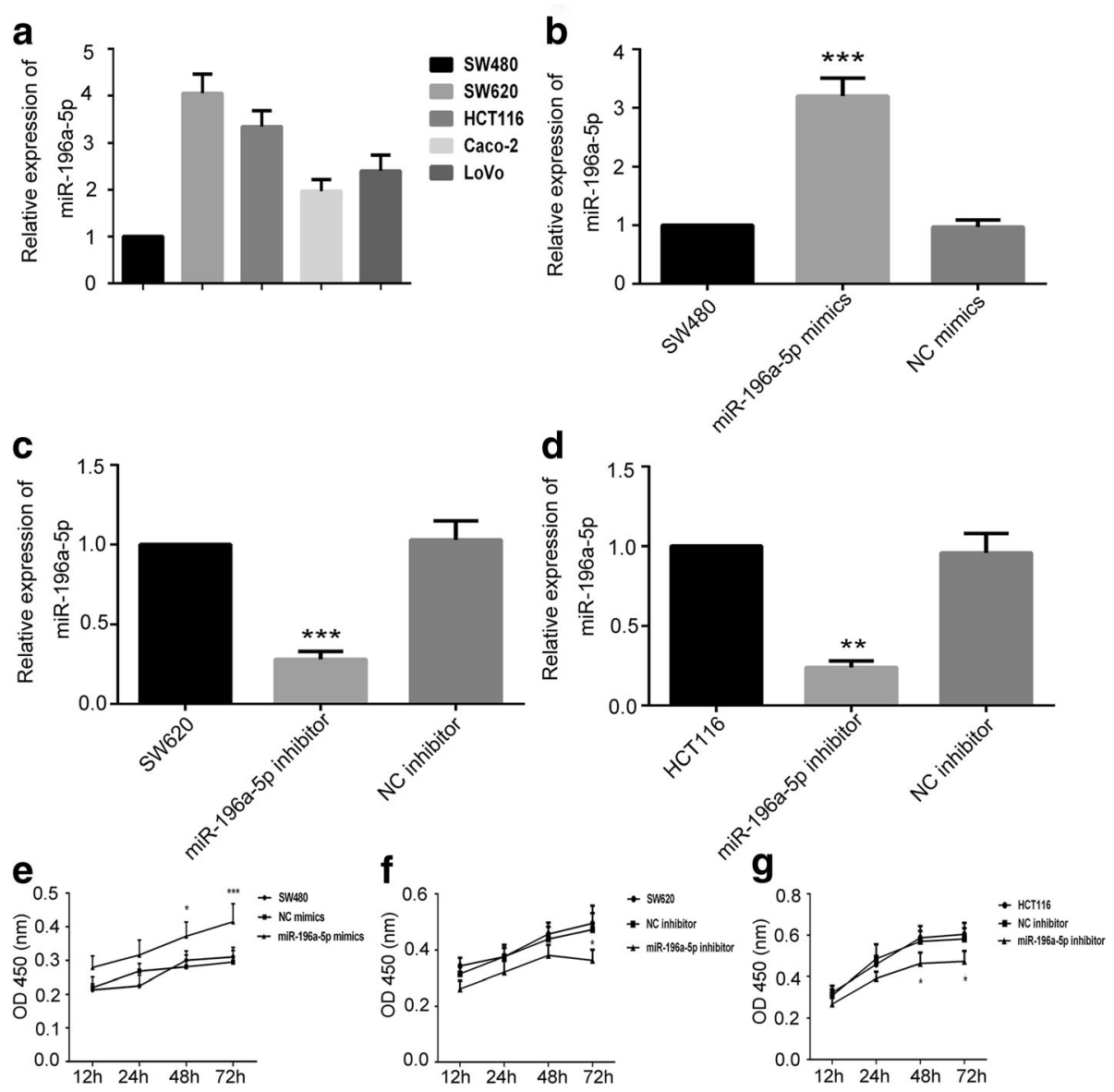

Fig. 1 The effects of miR-196a-5p on cell proliferation. a The expression level of miR-196a-5p in CRC cell lines. The expression of miR-196a-5p in b SW480, c SW620 and d HCT116 cells after transfection were measured by Real-time PCR. Cell viability of transfected e SW480, f SW620 and $\mathbf{g}$ HCT116 cells were determined by CCK-8 assay. Data were shown as mean $\pm S D$, ${ }^{* *} P<0.001$, ${ }^{* *} P<0.01$ and ${ }^{*} P<0.05$ compared to NC group 

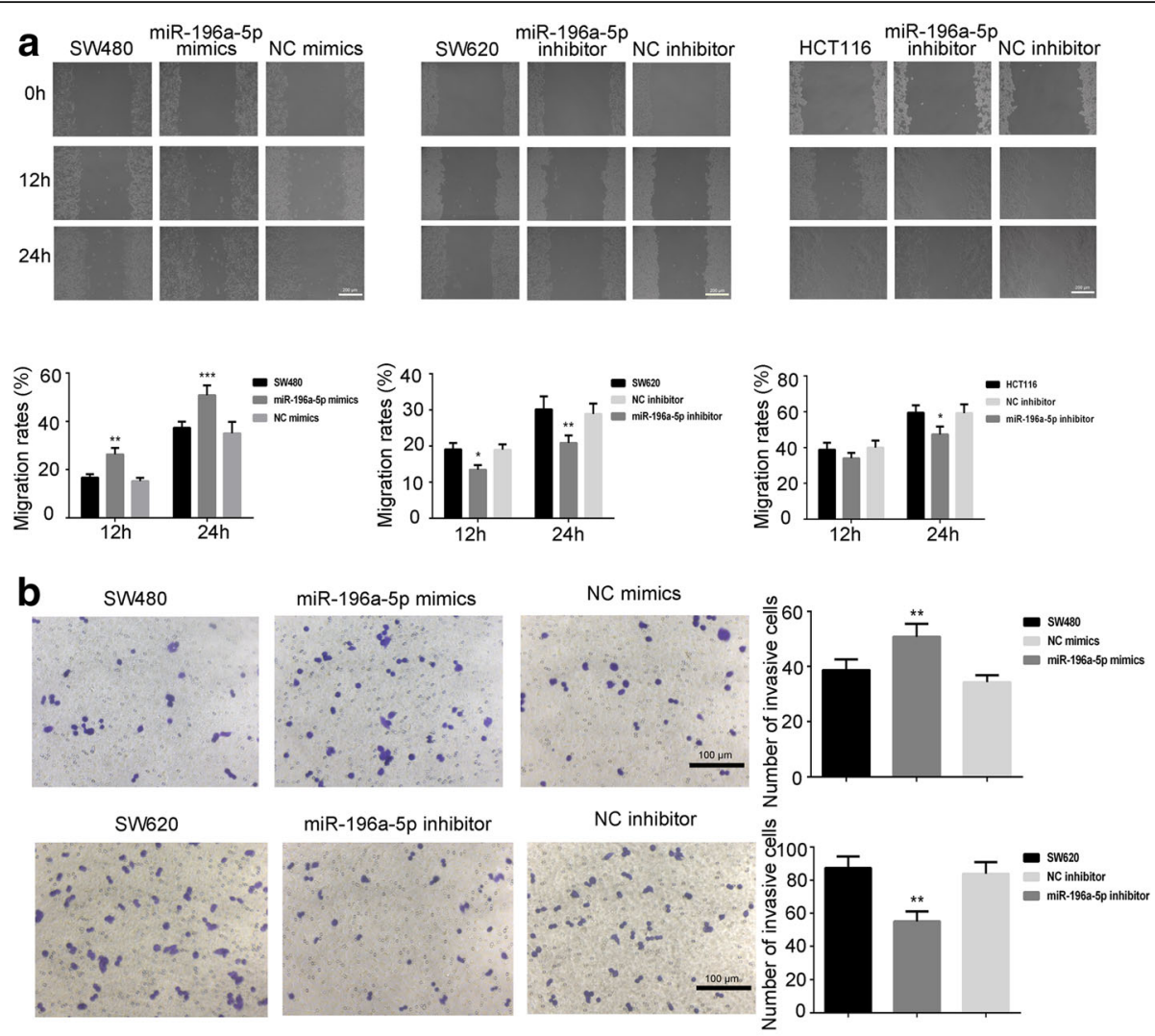

NC inhibitor
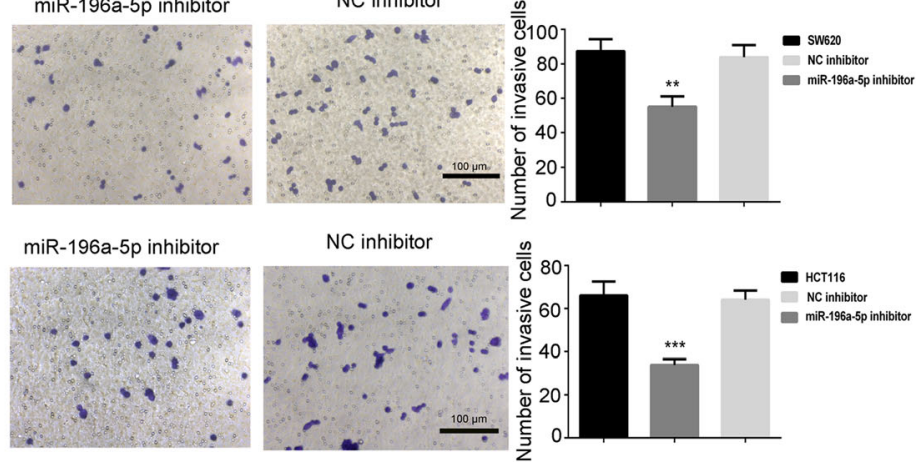

Fig. 2 The effects of miR-196a-5p on cell migration and invasion. a The representative images and analysis of wound healing assay in transfected CRC cells. $\mathbf{b}$ The representative images and analysis of trans-well invasion assay in CRC cells. Data were shown as mean $\pm S D$, ${ }^{* * *} P<0.001,{ }^{* *} P<0.01$ and ${ }^{*} P<0.05$ compared to NC group

miR-196a-5p aggravated the liver metastasis in vivo

The effects of miR-196a-5p on liver metastasis were also been evaluated in our present study. We firstly established SW480 cells stably over-expressed miR-196a-5p, and HCT-116 cells with miR-196a-5p knockdown (Fig. 3a). After injection these CRC cells into spleens for seven weeks, laparotomy was conducted. We observed that SW480 cells which overexpressed miR-196a-5p induced more metastatic nodules formation in liver, while knockdown of miR-196a-5p in HCT-116 cells attenuated the tumor metastasis (Fig. 3b). As shown in Fig. 3c, histologic analyses further verified that injection with miR-196a-5p-expressed CRC cells increased the number of micrometastatic lesions in liver, whereas injection of miR-196a-5p knockdown cells had opposite effects. The western blot results showed that the expression of $\mathrm{I} \kappa \mathrm{B} \alpha$ and E-cadherin was decreased, and
$\mathrm{N}$-cadherin was increased in liver metastatic nodules induced by miR-196a-5p overexpressing cells (Additional file 1a). Conversely, we found that $I \kappa B \alpha$ and E-cadherin protein levels were increased, and $\mathrm{N}$-cadherin protein levels were decreased in liver metastatic nodules induced by miR-196a-5p downregulated cells (Additional file 1b).

\section{miR-196a-5p promoted the epithelial-mesenchymal transition of CRC cells}

Western blot assay and immunofluorescence staining were performed to evaluate the effects of miR-196a-5p on the expression of epithelial markers E-cadherin and mesenchymal markers $\mathrm{N}$-cadherin and fibronectin. As shown in Fig. 4 and Fig. 5, over-expression of miR-196a-5p down-regulated the E-cadherin, whereas up-regulated the $\mathrm{N}$-cadherin and fibronectin. Contrastingly, E-cadherin was increased while $\mathrm{N}$-cadherin and 

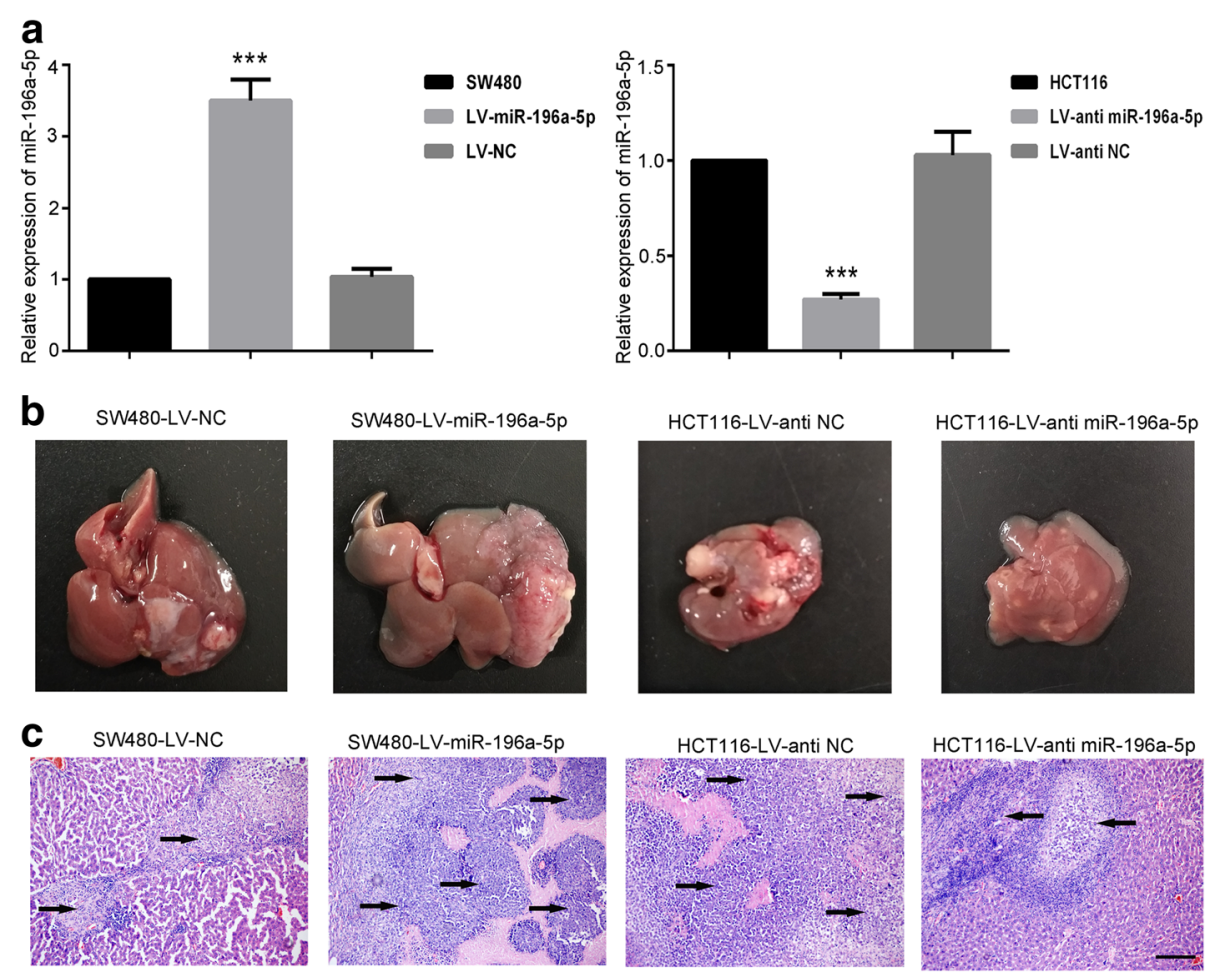

Fig. 3 The effects of miR-196a-5p on the liver metastasis of CRC. a The expression level of miR-196a-5p in infected CRC cells. $\mathbf{b}$ The representative images of macroscopic metastasis in the liver from mice injected CRC cells. $\mathbf{c} H \& E$ staining indicated the metastatic foci identified in the liver of mice after injection of CRC cells. Scalar bar: $200 \mu \mathrm{m}$. Data were shown as mean \pm SD, ${ }^{* * *} P<0.001$, compared to NC group
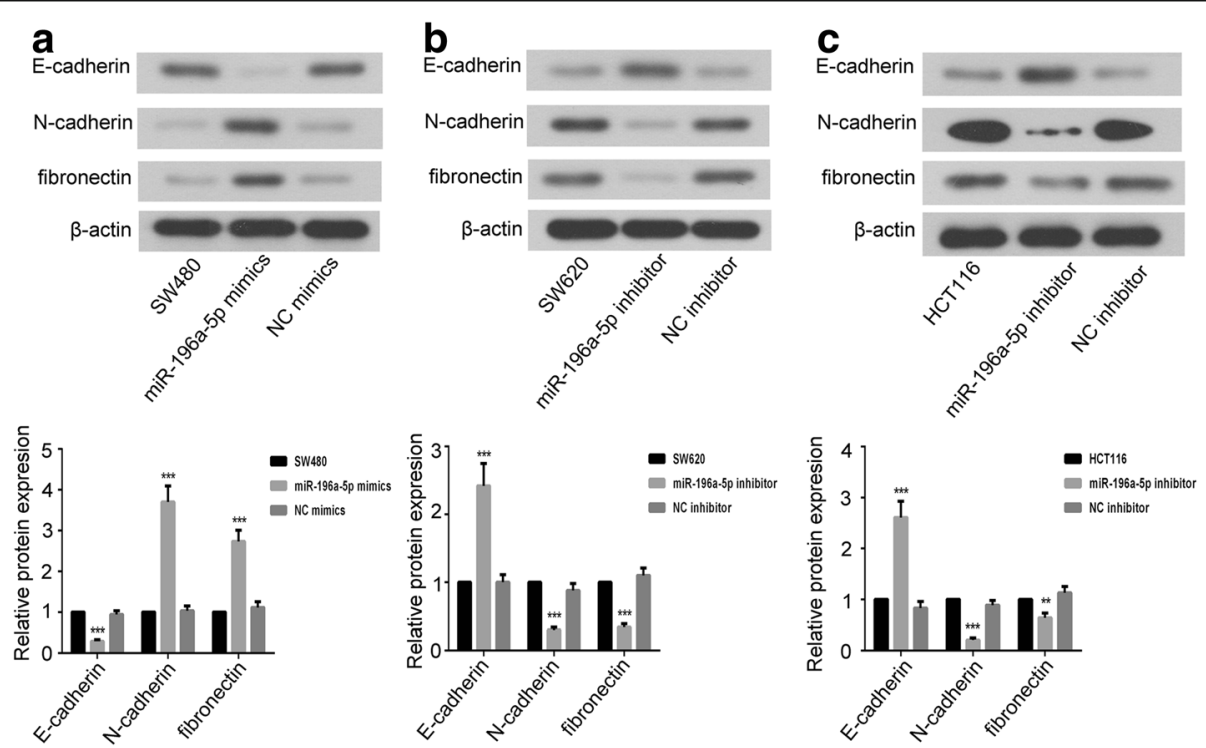

Fig. 4 The effects of miR-196a-5p on the expression of EMT-related proteins in CRC cells. The representative images and analysis of western blot for E-cadherin, N-cadherin, fibronectin in (a) SW480, (b) SW620 and (c) HCT116 cells. Data were shown as mean \pm SD, ${ }^{* * * P}<0.001$ and ${ }^{* * P}<0.01$ compared to NC group 


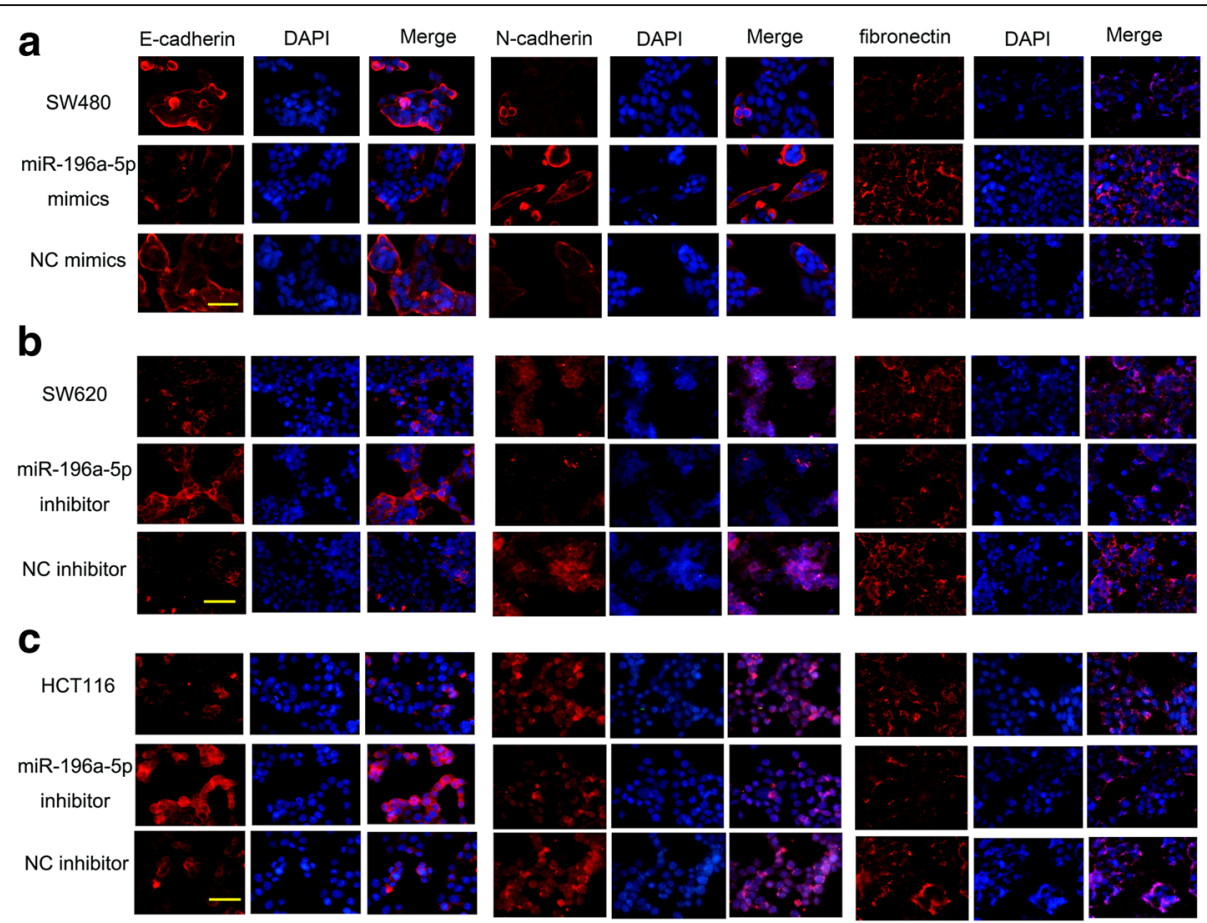

Fig. 5 The influence of miR-196a-5p on the EMT process of CRC cells. Immunofluorescence staining showed the expression of EMT-related markers in a SW480, b SW620 and c HCT116 cells after transfected with miR-196a-5p mimic or miR-196a-5p inhibitor. Scalar bar: 50 um

fibronectin were decreased in miR-196a-5p knockdown CRC cells.

\section{Inhibition of NF-KB signaling pathway suppressed the EMT of CRC cells}

We employed BAY 11-7082, the inhibitor of NF-kB signaling pathway, to investigate the role of NF-kB pathway in EMT. As shown in Fig. 6a, BAY 11-7082 decreased the phosphorylation level of $\mathrm{I} \mathrm{K} \mathrm{B} \alpha$ and nuclear expression of p65 in SW620 and HCT116 cells. BAY 11-7082 up-regulated the total expression level of IкB $\alpha$ in CRC cells. Furthermore, BAY 11-7082 increased the expression of E-cadherin whereas decreased the expression of $\mathrm{N}$-cadherin and fibronectin in both SW620 and HCT116 cells (Fig. 6b).

\section{miR-196a-5p promoted EMT and mobility of CRC cells via} targeting ІкBa

By analyzing the database of microrna.org, we found that IкB $\alpha$ may be a downstream target of the

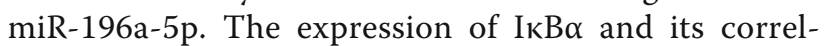
ation with miR-196a-5p were evaluated in CRC cells (Additional file 2). The result showed a negative correlation tendency between miR196 and IkB $\alpha$ expression in CRC cells $(r=-0.372)$, but no significance $(p$ $=0.54)$. We performed dual luciferase reporter assay to determine whether there was an interaction between I $\mathrm{B} \alpha \alpha$ mRNA and miR-196a-5p. As shown in
Fig. 7a, miR-196a-5p mimic decreased the luciferase activity of reporter containing 3'UTR of IKB $\alpha$, while miR-196a-5p mutant did not have similar effects. We found that induced the expression of miR-196a-5p down-regulated the IкB $\alpha$ both in mRNA and protein level, whereas miR-196a-5p knockdown had opposite effects (Fig. $7 \mathrm{~b}$ and $\mathrm{c}$ ). We further observed that over-expression of miR-196a-5p increased the nuclear p65 level, and knockdown of miR-196a-5p decreased the expression of nuclear p65 (Fig. 7c). Moreover, we

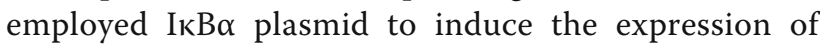
IкB $\alpha$ in SW480 cells (Additional file 3). As shown in Fig. $8 \mathrm{a}$ and $\mathrm{b}$, inducing the IKB $\alpha$ expression by trans-

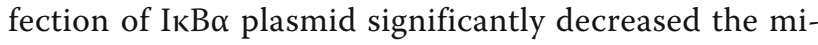
gration rate and number of invading cells in miR-196a-5p overexpressing SW480 cells. Further, over-expression of IKB $\alpha$ in miR-196a-5p overexpressing CRC cells increased E-cadherin levels and inhibited N-cadherin and fibronectin levels (Fig. 8c).

\section{Discussion}

Tumor metastasis seriously affects the prognosis of CRC patients [16]. While several studies indicated that miR-196a-5p was involved in the pathological process of CRC, the clear regulatory mechanisms of miR-196a-5p in CRC metastatic process have yet to be elucidated. The merit of our present work was firstly indicated that miR-196a-5p may target the I $k B \alpha$ 


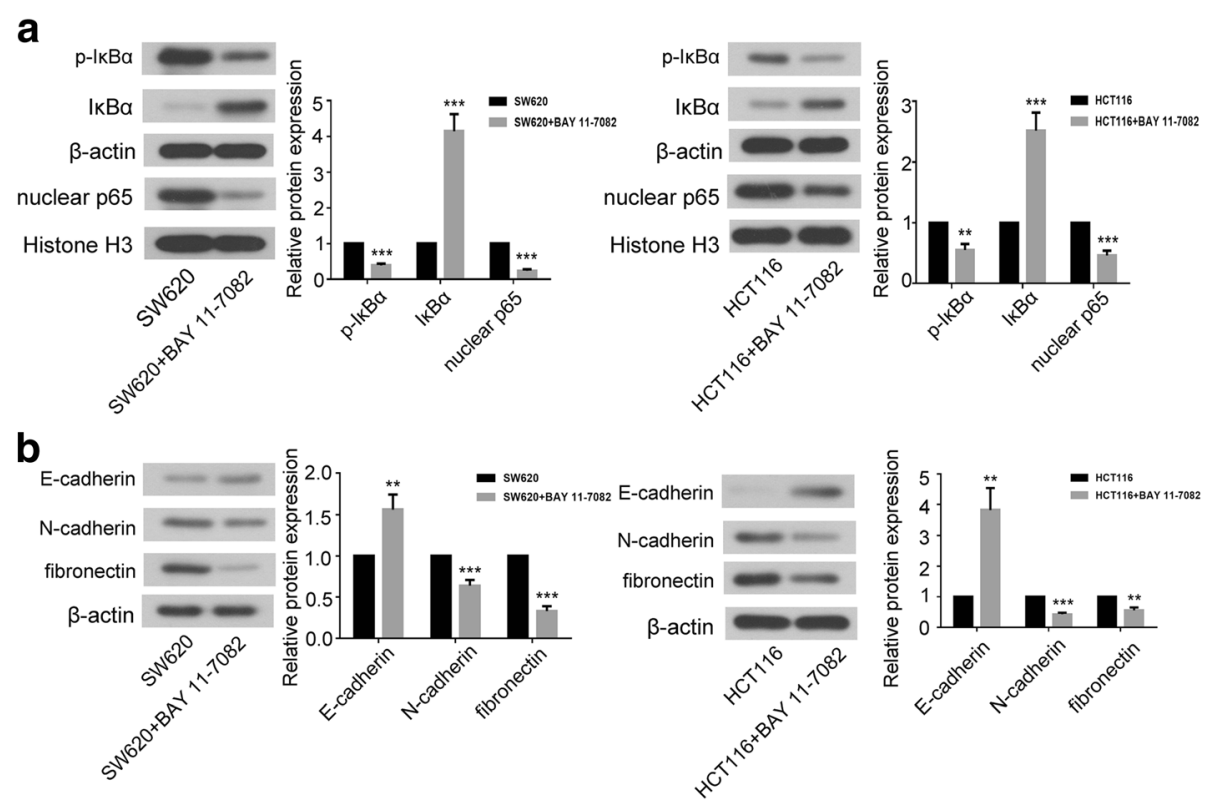

Fig. 6 The effects of NF-kB signaling pathway on EMT. a The representative images and analysis of western blot for $1 k B a, p-1 k B a$ and nuclear p65 in CRC cells treated with BAY 11-7082 (inhibitor of NF-KB pathway). $\mathbf{b}$ The expression levels of E-cadherin, N-cadherin and fibronectin in SW620 and HCT116 cells were measured by western blot. Data were shown as mean \pm SD, ${ }^{* *} P<0.001$ and ${ }^{* *} P<0.01$ compared to non-treated group

to regulate the EMT process and finally promoted CRC cells invasion and metastasis.

The miR-196a-5p was initially identified as an oncogenic miRNA which direct targeted annexin A1 to promote proliferation and prevent apoptosis of esophageal cancer cells [17]. With further investigations, researchers found that miR-196a-5p was aberrant expression in various cancer tissues such as cervical cancer and non-small cell lung cancer, and its expression level was correlated with the progression of these cancers $[18,19]$. For instance, miR-196a-5p was significantly over-expressed in the oral cancer tissues and it accelerated the cell migration and invasion of oral cancer cells through the NME4-JNK-TIMP1-MMP axis [20]. Intriguingly, one study from Schimanski [21] and his colleagues demonstrated that miR-196a-5p was up-regulated in CRC samples and it played a pro-oncogenic role by reinforcing CRC cells invasion and their sensitivity to the platinum derivatives. They also observed that over-expression of miR-196a-5p enhanced the lung metastases of CRC in vivo. In line with these, our work demonstrated that over-expression of miR-196a-5p promoted the proliferation, migration, invasion and the liver metastasis of CRC cells, indicating that hyper proliferated CRC cells by miR196 may show an increase in cell migration and liver metastasis, while miR-196a-5p knockdown attenuated the cell viability, invasion and metastasis of CRC cells. These results confirmed the oncogenic effects of miR-196a-5p, especial the pro-metastatic effects.
Epithelial-mesenchymal transition is a reversible process which is been considered as a critical program during the metastatic cascade in several types of cancers including the CRC $[22,23]$. During this process, cells suppressed the E-cadherin and expressed the mesenchymal proteins such as $\mathrm{N}$-cadherin, fibronectin to loss the cell-cell adhesion and acquire migratory and invasive abilities [24, 25]. Inspired by these, we evaluated the effects of miR-196a-5p on the EMT process of CRC. As expected, inducing expression of miR-196a-5p in CRC cells promoted the EMT by down-regulating E-cadherin while up-regulating $\mathrm{N}$-cadherin and fibronectin, whereas silencing of miR-196a-5p exerted opposite effects. The above investigations suggested that promoting the EMT contributed a lot to the pro-metastatic effects of miR-196a-5p in CRC.

It is worth mentioning that several literatures demonstrated that IкB $\alpha$ may work as a downstream target of miR-196a-5p during cancer progression. One study from Yang et al showed that miR-196a took an oncogenic role in glioblastoma multiforme by targeting I $\mathrm{I} B \alpha$ [26]. The I $\mathrm{B} \alpha$ is a negative regulator of the NF- $\mathrm{B} B$ signaling pathway. After being phosphorylated and degraded by stimu-

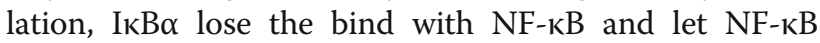
translocate to nucleus to activate the target genes [27, 28]. Moreover, it has been showed that suppressing the phosphorylation of ІкB $\alpha$ may partially inhibit the invasion and EMT of gastric cancer cells [29]. In non-small cell lung cancer cells, preventing the phosphorylation of 

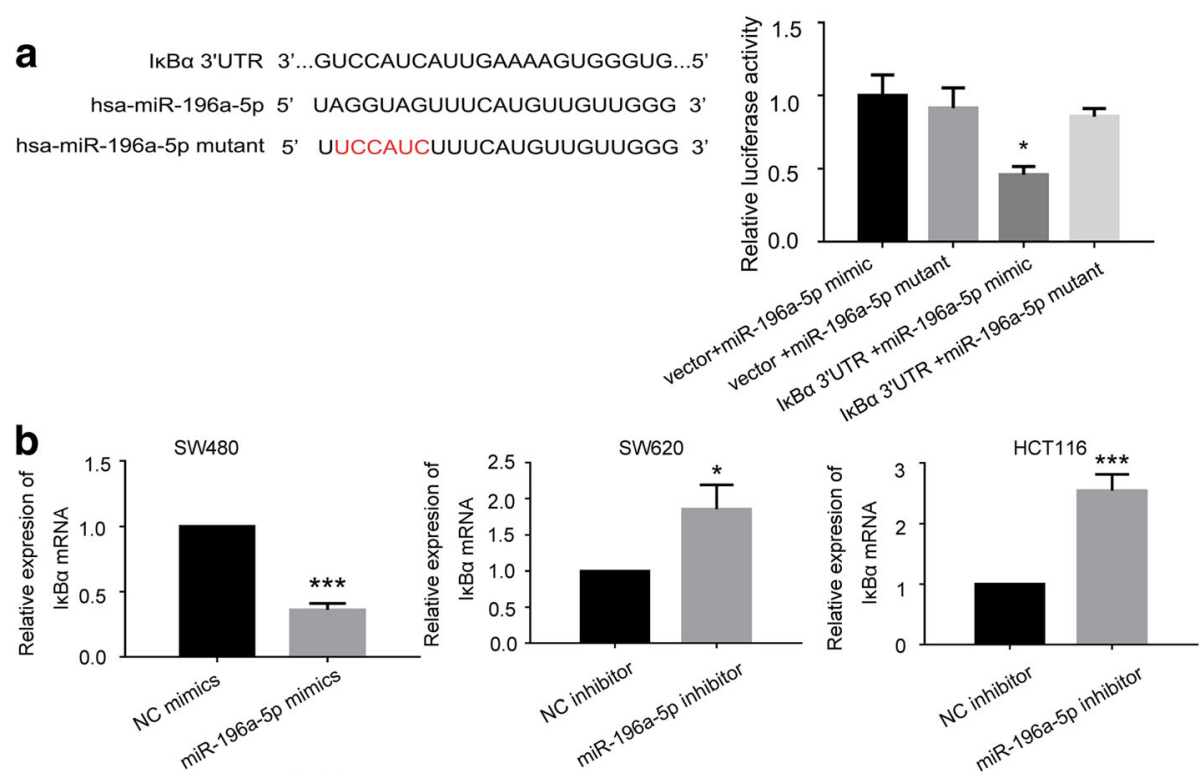

C
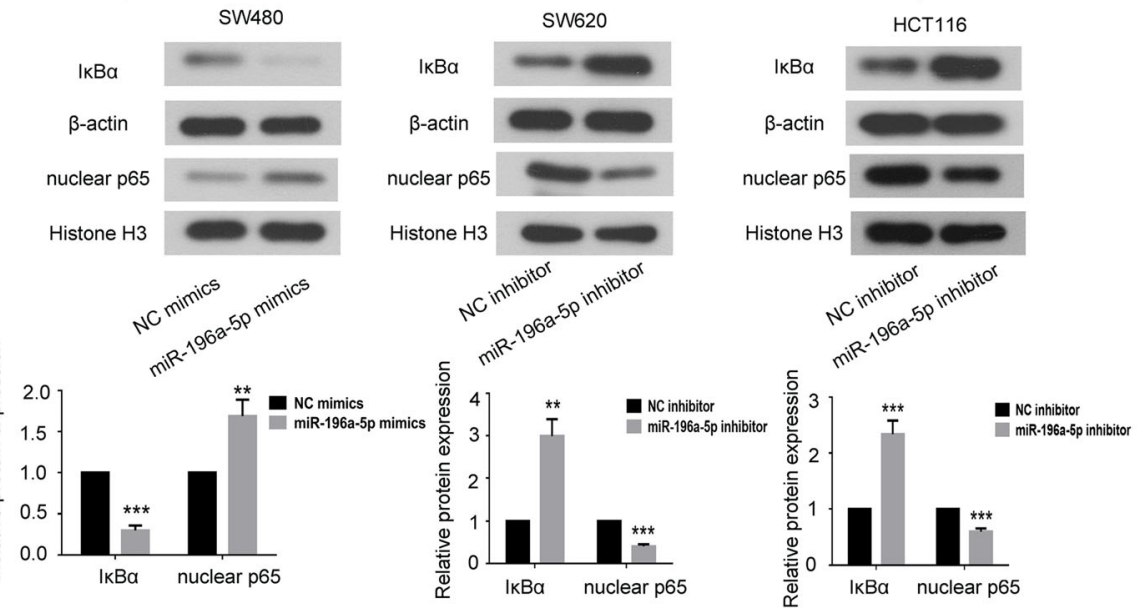

Fig. $7 \mathrm{kBBa}$ was a target of the miR-196a-5p. a The predicted seed region of $\mathrm{lkBa}$ bound to miR-196a-5p and the mutated sequence used in present work was shown at left. The luciferase activity was measured at $48 \mathrm{~h}$ after HEK293 cells cotransfected with vector/miR-196a-5p mimic, IKBa-WT/miR196a-5p mimic or IkBa-WT/miR-196a-5p-mutant plasmid. $\mathbf{b}$ The expression of IkBa mRNA in CRC cells after transfection. $\mathbf{c}$ The effects of miR-196a-5p on the expression of $\mathrm{IKBa}$ and nuclear p65 were determined by western blot. Data were shown as mean $\pm \mathrm{SD},{ }^{* *} P<0.001,{ }^{* *} P<0.01$ and ${ }^{*} P<0.05$ compared to NC group

I $\mathrm{B} \alpha$ and the subsequently activation of NF- $\kappa \mathrm{B}$ was benefit for suppressing the EMT process [30].

Consideration of above observations, we speculated miR-196a-5p may also facilitate the EMT of CRC via regulating the I $\mathrm{kB} \alpha$ expression. By performing the dual luciferase reporter assay, we verified that miR-196a-5p directly bound to the I $\kappa \beta \alpha$ gene. We also investigated

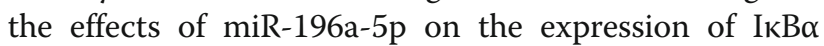
pathway. As expected, miR-196a-5p over-expression decreased the expression of IкB $\alpha$ and increased the level of nuclear p65, while miR-196a-5p knockdown up-regulated the IкB $\alpha$ and down-regulated the nuclear p65 in CRC cells. The data suggested that IкB $\alpha$ may be a target of the miR-196a-5p in CRC cells.
We further evaluated that whether inhibition of the NF- $\mathrm{kB}$ pathway attenuated the EMT of CRC. The results demonstrated that deactivation of NF- $\mathrm{KB}$ pathway increased epithelial markers E-cadherin but decreased the mesenchymal markers $\mathrm{N}$-cadherin and fibronectin. As I $\mathrm{B} \alpha$ is the natural inhibitor of NF- $\mathrm{B} B$ signaling pathway, these findings implied that miR-196a-5p and IкB $\alpha$ may take opposite roles in the EMT of CRC. Additionally, over-expression of $\mathrm{I} \kappa \mathrm{B} \alpha$ in $\mathrm{CRC}$ cells attenuated miR-196a-5p induced-migration, invasion and EMT of CRC cells, which further confirmed that miR-196a-5p exerted its pro-metastatic effects by facilitating the EMT process via targeting I $\mathrm{\kappa} B \alpha$. In order to further clarify the pro-metastatic effects and the potential mechanisms of 


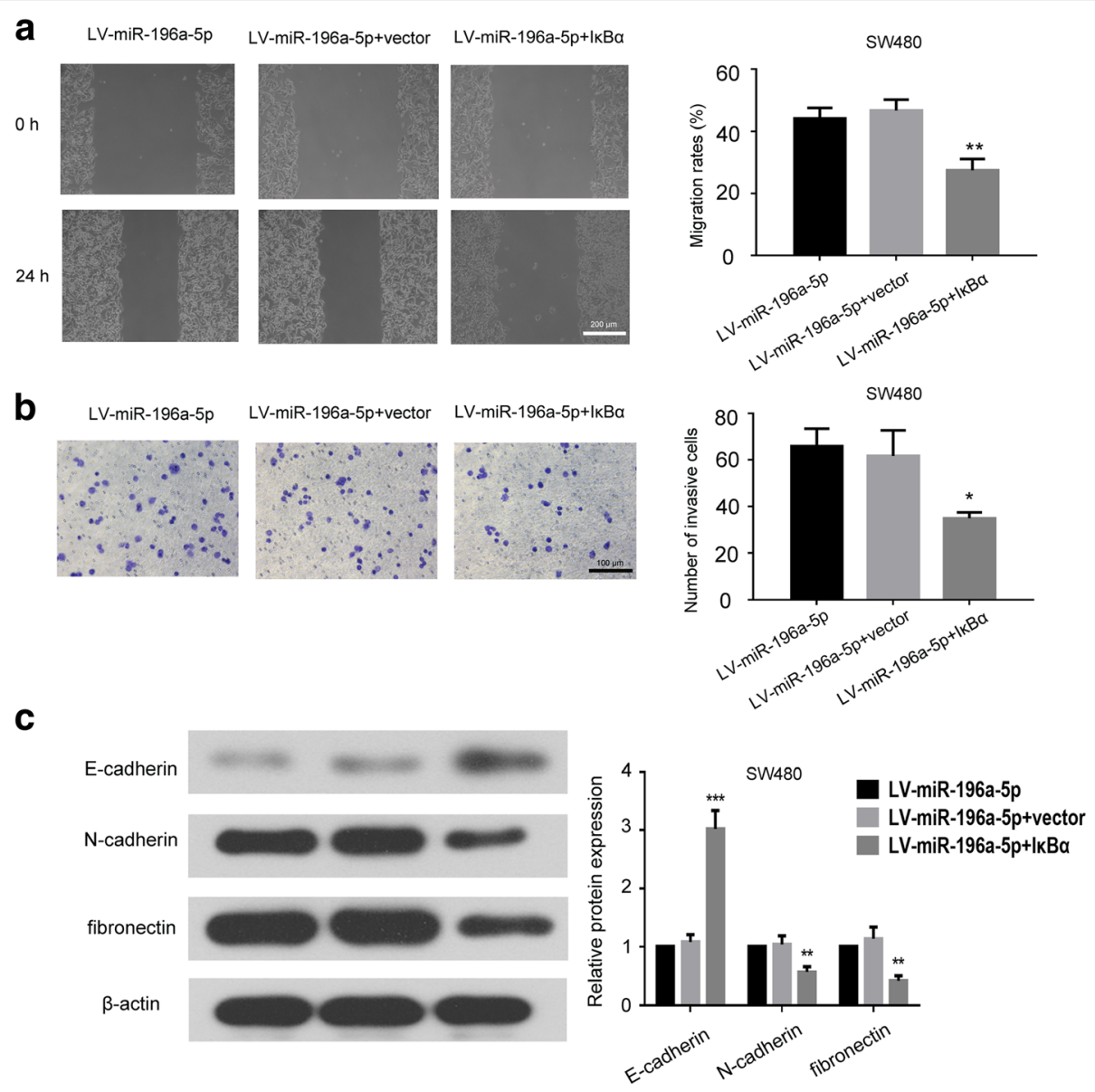

Fig. 8 miR-196a-5p promoted the migration, invasion and EMT of CRC cells via targeting IKBa. a The representative images and analysis of wound healing assay in CRC cells after transfection. $\mathbf{b}$ The representative images and analysis of trans-well invasion assay in CRC cells. $\mathbf{c}$ The expression level of EMT-related proteins in transfected CRC cells were determined by western blot. ${ }^{* *} P<0.001,{ }^{* *} P<0.01$ and ${ }^{*} P<0.05$ compared to LV-miR-196a-5p + vector group

miR-196a-5p in CRC, we will perform clinical studies to analyze the correlation between miR-196a-5p levels and liver metastasis. The relationship between the expression of miR-196a-5p and IkBa in the clinical CRC tissues will also be investigated in future.

\section{Conclusions}

In conclusion, our data demonstrates that miR-196a-5p facilitates the proliferation, metastasis and invasion of CRC cells. Additionally, the pro-metastatic property of miR-196a-5p is exerted through regulating the EMT process via targeting the IкB $\alpha$. Our findings suggest that regulating miR-196a-5p may be a potential strategy to ameliorate the tumor metastasis of CRC.

\section{Additional files}

Additional file 1: Western blot assay was employed to evaluate the expression levels of $\mathrm{KBBa}, \mathrm{E}$-cadherin and $\mathrm{N}$-cadherin in liver metastatic nodules induced by (a) miR-196a-5p overexpressing or (b) miR-196a-5p downregulated CRC cells. ${ }^{* * *} P<0.001$ compared to LV-NC or LV-anti-NC group. (TIF $1803 \mathrm{~kb}$ )

Additional file 2: (a) The mRNA level of IKBa in CRC cell lines. (b) The correlation between miR-196a-5p and IkBa mRNA levels in CRC cells. (TIF $718 \mathrm{~kb}$ )

Additional file 3: Transfection of $\mathrm{I} \mathrm{KB}$ a plasmid induced the expression of IKBa in SW480 cells. (a) The protein level of IKBa in SW480 cells. (b) The mRNA level of IKBa in SW480 cells. ${ }^{* * *} P<0.001$ compared to vector group. (TIF $1284 \mathrm{~kb}$ )

\section{Abbreviations}

CRC: Colorectal cancer; EMT: Epithelial-mesenchymal transition; miRNAs: microRNAs

\section{Acknowledgements}

Not applicable.

\section{Funding}

This study was funded by a grant from the National Natural Science Foundation of China (project No. 81470086). 


\section{Availability of data and materials}

The datasets supporting the conclusions of the current study are available from the corresponding author on reasonable request. Please contact corresponding author, if you want to request the dataset.

\section{Authors' contributions}

ZYL designed the experiment. HX and CZW performed the experiments. $\mathrm{HX}$ analyzed the data and wrote the manuscript. All authors have read the manuscript and approved of the version to be published.

\section{Ethics approval}

All procedures performed in studies involving animals were approved by Medical Ethics Committee of Shengjing Hospital of China Medical University following the Guide for the Care and Use of Laboratory Animals.

\section{Competing interests}

The authors declare that they have no competing interests.

\section{Publisher's Note}

Springer Nature remains neutral with regard to jurisdictional claims in published maps and institutional affiliations.

\section{Received: 23 August 2018 Accepted: 21 December 2018}

\section{Published online: 08 January 2019}

\section{References}

1. Brenner H, Kloor M, Pox CP. Colorectal cancer. Lancet. 2014;383(9927): 1490-502.

2. Kekelidze M, D'Errico L, Pansini M, Tyndall A, Hohmann J. Colorectal cancer: current imaging methods and future perspectives for the diagnosis, staging and therapeutic response evaluation. World I Gastroenterol. 2013;19(46): 8502-14.

3. Worni M, Shah KN, Clary BM. Colorectal cancer with potentially resectable hepatic metastases: optimizing treatment. Curr Oncol Rep. 2014;16(10):407.

4. Van Cutsem E, Oliveira J. Advanced colorectal cancer: ESMO clinical recommendations for diagnosis, treatment and follow-up. Ann Oncol. 2009; 20(Suppl 4):61-3.

5. Li S, Wang J, Lu Y, Fan D. Screening and early diagnosis of colorectal cancer in China: a 12 year retrospect (1994-2006). J Cancer Res Clin Oncol. 2007; 133(10):679-86

6. Garzon R, Marcucci G, Croce CM. Targeting microRNAs in cancer: rationale, strategies and challenges. Nat Rev Drug Discov. 2010;9(10):775-89.

7. Stark A, Brennecke J, Bushati N, Russell RB, Cohen SM. Animal MicroRNAs confer robustness to gene expression and have a significant impact on 3'UTR evolution. Cell. 2005;123(6):1133-46.

8. Zhao S, Sun H, Jiang W, Mi Y, Zhang D, Wen Y, et al. miR-4775 promotes colorectal cancer invasion and metastasis via the Smad7/TGFbeta-mediated epithelial to mesenchymal transition. Mol Cancer. 2017:16(1):12.

9. Ge J, Chen Z, Li R, Lu T, Xiao G. Upregulation of microRNA-196a and microRNA-196b cooperatively correlate with aggressive progression and unfavorable prognosis in patients with colorectal cancer. Cancer Cell Int. 2014;14(1):128.

10. Ye Y, Yang S, Han Y, Sun J, Xv L, Wu L, et al. Linc00472 suppresses proliferation and promotes apoptosis through elevating PDCD4 expression by sponging miR-196a in colorectal cancer. Aging (Albany NY). 2018;10(6):1523-33

11. Karin M, Greten FR. NF-kappaB: linking inflammation and immunity to cancer development and progression. Nat Rev Immunol. 2005;5(10):749-59.

12. Wang $Y$, Xu H, Jiao $H$, Wang $S$, Xiao Z, Zhao $Y$, et al. STX2 promotes colorectal cancer metastasis through a positive feedback loop that activates the NF-kappaB pathway. Cell Death Dis. 2018;9(6):664.

13. Feng M, Feng J, Chen W, Wang W, Wu X, Zhang J, et al. Lipocalin2 suppresses metastasis of colorectal cancer by attenuating NF-kappaBdependent activation of snail and epithelial mesenchymal transition. Mol Cancer. 2016;15(1):77.

14. Liang F, Liang J, Wang WQ, Sun JP, Udho E, Zhang ZY. PRL3 promotes cell invasion and proliferation by down-regulation of Csk leading to Src activation. J Biol Chem. 2007;282(8):5413-9.

15. Kubens BS, Zanker KS. Differences in the migration capacity of primary human colon carcinoma cells (SW480) and their lymph node metastatic derivatives (SW620). Cancer Lett. 1998;131(1):55-64.
16. Muhammad S, Kaur K, Huang R, Zhang Q, Kaur P, Yazdani HO, et al. MicroRNAs in colorectal cancer: role in metastasis and clinical perspectives. World J Gastroenterol. 2014;20(45):17011-9.

17. Luthra R, Singh RR, Luthra MG, Li YX, Hannah C, Romans AM, et al. MicroRNA-196a targets annexin A1: a microRNA-mediated mechanism of annexin A1 downregulation in cancers. Oncogene. 2008;27(52):6667-78.

18. Liu XH, Lu KH, Wang KM, Sun M, Zhang EB, Yang JS, et al. MicroRNA-196a promotes non-small cell lung cancer cell proliferation and invasion through targeting HOXA5. BMC Cancer. 2012;12:348.

19. Zhang J, Zheng F, Yu G, Yin Y, Lu Q. miR-196a targets netrin 4 and regulates cell proliferation and migration of cervical cancer cells. Biochem Biophys Res Commun. 2013;440(4):582-8.

20. Lu YC, Chang JT, Liao CT, Kang CJ, Huang SF, Chen IH, et al. OncomiR-196 promotes an invasive phenotype in oral cancer through the NME4-JNKTIMP1-MMP signaling pathway. Mol Cancer. 2014;13:218.

21. Schimanski CC, Frerichs K, Rahman F, Berger M, Lang H, Galle PR, et al. High miR-196a levels promote the oncogenic phenotype of colorectal cancer cells. World J Gastroenterol. 2009;15(17):2089-96.

22. Loboda A, Nebozhyn MV, Watters JW, Buser CA, Shaw PM, Huang PS, et al. EMT is the dominant program in human colon cancer. BMC Med Genet. 2011;4:9.

23. Li L, Li W. Epithelial-mesenchymal transition in human cancer: comprehensive reprogramming of metabolism, epigenetics, and differentiation. Pharmacol Ther. 2015;150:33-46.

24. Cano A, Perez-Moreno MA, Rodrigo I, Locascio A, Blanco MJ, del Barrio MG, et al. The transcription factor snail controls epithelialmesenchymal transitions by repressing E-cadherin expression. Nat Cell Biol. 2000;2(2):76-83.

25. Wheelock MJ, Shintani Y, Maeda M, Fukumoto Y, Johnson KR. Cadherin switching. J Cell Sci. 2008;121(Pt 6):727-35.

26. Yang G, Han D, Chen X, Zhang D, Wang L, Shi C, et al. MiR-196a exerts its oncogenic effect in glioblastoma multiforme by inhibition of IkappaBalpha both in vitro and in vivo. Neuro-Oncology. 2014;16(5):652-61.

27. Viatour P, Merville MP, Bours V, Chariot A. Phosphorylation of NF-kappaB and IkappaB proteins: implications in cancer and inflammation. Trends Biochem Sci. 2005;30(1):43-52.

28. Karin M, Cao Y, Greten FR, Li ZW. NF-kappaB in cancer: from innocent bystander to major culprit. Nat Rev Cancer. 2002;2(4):301-10.

29. Ji L, Zhang B, Zhao G. Liver X receptor alpha (LXRalpha) promoted invasion and EMT of gastric cancer cells by regulation of NF-kappaB activity. Hum Cell. 2017;30(2):124-32.

30. Lu Z, Li Y, Wang J, Che Y, Sun S, Huang J, et al. Long non-coding RNA NKILA inhibits migration and invasion of non-small cell lung cancer via NFkappaB/snail pathway. J Exp Clin Cancer Res. 2017;36(1):54.

Ready to submit your research? Choose BMC and benefit from:

- fast, convenient online submission

- thorough peer review by experienced researchers in your field

- rapid publication on acceptance

- support for research data, including large and complex data types

- gold Open Access which fosters wider collaboration and increased citations

- maximum visibility for your research: over $100 \mathrm{M}$ website views per year

At BMC, research is always in progress.

Learn more biomedcentral.com/submissions 